Article

\title{
Evaluation of Different Clinoptilolite Zeolites as Adsorbent for Ammonium Removal from Highly Concentrated Synthetic Wastewater
}

\author{
Stephan Wasielewski ${ }^{1, *}$, Eduard Rott ${ }^{1}$ (D), Ralf Minke ${ }^{1}$ and Heidrun Steinmetz ${ }^{2}$ \\ 1 Institute for Sanitary Engineering, Water Quality and Solid Waste Management (ISWA), \\ University of Stuttgart, Bandtaele 2, 70569 Stuttgart, Germany; eduard.rott@iswa.uni-stuttgart.de (E.R.); \\ ralf.minke@iswa.uni-stuttgart.de (R.M.) \\ 2 Faculty of Civil Engineering, University of Kaiserslautern, Paul-Ehrlich-Str. 14, 67663 Kaiserslautern, Germany; \\ heidrun.steinmetz@bauing.uni-kl.de \\ * Correspondence: stephan.wasielewski@iswa.uni-stuttgart.de; Tel.: +49-711-685-65425
}

Received: 3 April 2018; Accepted: 25 April 2018; Published: 30 April 2018

\begin{abstract}
The supply of food to the growing world population requires an increasing amount of nitrogen fertilizers, which can be achieved both by the energy-intensive Haber-Bosch process and by recovering ammonium from wastewater. Within the scope of this work, it is investigated to what extent different clinoptilolites (CLIs) can be used as ion-exchangers for the removal of ammonium from highly concentrated solutions. To this end, finely ground CLIs with different grain sizes (EcoZeo 20 and CCP 20: 0-20 $\mu \mathrm{m}$, Micro 200: 0-200 $\mu \mathrm{m}$ ) were tested for their sorption properties by varying the parameters of the sorption solution $\left(\mathrm{c}_{0}=1000 \mathrm{mg} \mathrm{NH}_{4}-\mathrm{N} / \mathrm{L}\right)$ such as $\mathrm{pH}$, temperature, or contact time. All three CLIs tested were effective at adsorbing ammonium. In a $\mathrm{pH}$ range from 2 to 8 , all CLIs were able to eliminate ammonium equally well. Furthermore, a contact time of 60 min was sufficient to achieve $84-88 \%$ of the maximum load. At a temperature of $34{ }^{\circ} \mathrm{C}$, the highest loading was achieved (investigated range: $10-34^{\circ} \mathrm{C}$ ), indicating that the adsorption process of all CLIs was exergonic and exothermic. Especially for wastewater streams with high ammonium concentrations such as sludge water from wastewater treatment plants, CLI proved to be suitable to adsorb ammonium.
\end{abstract}

Keywords: ammonia; ammonium recovery; Freundlich; intraparticle diffusion; isoelectric state; Langmuir; pseudo-second-order; Temkin; zeolite

\section{Introduction}

By 2050, the world's population is expected to grow from 7.6 billion in 2017 to $9.4-10.2$ billion people [1]. Due to the increasing population as well as other factors such as rising living standards, often correlating with increasing meat consumption, the demand for food and agricultural products is expected to increase by 50\% between 2012 and 2050. The adherence to increasing food requirements will not be achieved solely through the exploitation of new arable land as most of it is not developed, too remote from potential markets, susceptible to pest infestation, or competes with the conservation of important ecosystems. Furthermore, potential arable land is limited to a small number of countries. Rather, the increased demand for food must be met by increasing productivity and efficiency in agricultural production [2], which leads to a greater need for nutrients, especially nitrogen fertilizers.

The Haber-Bosch process, which enables the synthesis of ammonia $\left(\mathrm{NH}_{3}\right)$ for fertilizer production, ensures the nutrition of half the world's population [3]. However, the production of $\mathrm{NH}_{3}$ requires a high amount of energy [4]. Dawson and Hilton [5] calculated that $1.1 \%$ of the world's energy 
consumption can be attributed to the production of fertilizers; $90 \%$ of this is due to the production of nitrogen fertilizers. Thus, partial substitution of the increasing demand for $\mathrm{NH}_{3}$ may be achieved by recovering ammonium $\left(\mathrm{NH}_{4}^{+}\right)$from wastewater. For instance, sludge water from anaerobic digesters is a possible source of ammonium due to high ammonium-N $\left(\mathrm{NH}_{4}-\mathrm{N}\right)$ concentrations of around $1000 \mathrm{mg} / \mathrm{L}$ and low volume flows which allow a partial flow treatment.

Recovery methods such as air stripping, bioelectrochemical systems, membrane separation, and ion exchange have been thoroughly investigated [6]. The zeolite clinoptilolite (CLI) is known to be a very good ion exchanger, as it consists of a three-dimensional structure formed of $\mathrm{AlO}_{4}{ }^{-}$and $\mathrm{SiO}_{4}$ tetrahedral, which are connected by a common oxygen atom. The micropores formed by this structure are fine enough to allow cations and water molecules to enter and be exchanged [7]. This ability is based on the substitution of $\mathrm{SiO}_{4}$ by $\mathrm{AlO}_{4}{ }^{-}$, creating a negative charge, which has to be compensated by exchangeable cations such as $\mathrm{Na}^{+}, \mathrm{K}^{+}, \mathrm{Ca}^{2+}$, and $\mathrm{Mg}^{2+}$ [8].

As soon as the exchange capability for ammonium is exhausted, CLI is proposed to be utilized as a slow-release fertilizer in agriculture [9] or regenerated by the use of sodium chloride, sodium carbonate, sodium bicarbonate, and sodium hydroxide solutions [10-13].

While the ability of ammonium adsorption by zeolites was the focus of recent investigations, most of these investigations were carried out with one type of CLI from one specific deposit only [10,14-20], focusing on the composition of the CLI, the adsorption/elimination of ammonium at different $\mathrm{pH}$ values, describing the adsorption process, the kinetics using different models, and evaluation of the thermodynamic properties of the adsorption process.

In most cases, the methods chosen differed significantly (e.g., investigated particle size, contact time, initial $\mathrm{NH}_{4}-\mathrm{N}$ concentration), which is why a direct comparison of the investigated CLI, e.g., in terms of adsorption properties of ammonium from highly concentrated wastewater, is difficult. An overview of published data about CLI adsorption of ammonium is given in Table 1, showing the large variety of parameters examined, such as particle size $(0.063-1.43 \mathrm{~mm})$, contact time (20 min-24 h), and initial $\mathrm{NH}_{4}-\mathrm{N}$ concentration ranges (e.g., $25-150 \mathrm{mg} / \mathrm{L}$ vs. $10-5000 \mathrm{mg} / \mathrm{L}$ ). However, it cannot be deduced from these investigations to what extent each parameter has an effect on the adsorption capacity. Hence, it becomes apparent that there is still a lack of detailed comparisons regarding the adsorption properties of CLI.

Using three CLIs from a mining area in Slovakia, from which CLI with a high adsorption has been reported [10], this paper demonstrates in which way an analysis of adsorption properties from highly concentrated wastewater can be set up. The main aim of this research was to gain a deeper understanding of the adsorption process of ammonium from highly concentrated solutions, as well as to identify different properties (exchangeable cations, cation exchange capacity, and isoelectric $\mathrm{pH}$ ) regarding the tested CLI. In further experiments, the effects of temperature (determination of isotherms by varying the sorbent mass at different temperatures) and contact time (determination of kinetics by varying the contact time at room temperature) on the adsorption process were investigated. All experiments were conducted as triplicates.

This procedure could be used as a uniform guideline for future studies comparing different CLIs in terms of adsorption properties to adsorb ammonium from highly concentrated wastewater. 
Table 1. Overview of constraints and coefficients of isotherms according to Langmuir and Freundlich in different studies investigating the adsorption of ammonium onto clinoptilolite.

\begin{tabular}{|c|c|c|c|c|c|c|c|c|c|c|c|}
\hline \multirow{3}{*}{$\begin{array}{l}\text { Country } \\
\text { (Area) }\end{array}$} & \multirow{3}{*}{$\begin{array}{c}\text { Particle Size } \\
d_{P} \\
{[\mathrm{~mm}]}\end{array}$} & \multirow{3}{*}{$\begin{array}{c}\text { CLI } \\
\text { Share } \\
{[\%]}\end{array}$} & \multirow{3}{*}{$\begin{array}{c}\text { Initial } \\
\text { Concentration } \\
{\left[\mathrm{mg} \mathrm{NH}_{4}-\mathrm{N} / \mathrm{L}\right]}\end{array}$} & \multirow{3}{*}{ Contact Time } & \multicolumn{3}{|c|}{ Langmuir } & \multicolumn{3}{|c|}{ Freundlich } & \multirow{3}{*}{ Reference } \\
\hline & & & & & $\mathrm{K}_{\mathrm{L}}$ & $q_{\max }$ & $r^{2}$ & $\mathrm{~K}_{\mathrm{F}}$ & $1 / n$ & $r^{2}$ & \\
\hline & & & & & {$[\mathrm{L} / \mathrm{g}]$} & {$[\mathrm{mg} / \mathrm{g}]$} & {$[-]$} & {$[\mathrm{L} / \mathrm{g}]$} & {$[-]$} & {$[-]$} & \\
\hline Slovakia (-) & $<0.2$ & - & $10-5000$ & over night & 0.006 & 33 & 0.99 & 1.84 & 0.36 & 0.97 & [10] \\
\hline China (Huludao) & $0.063-0.073$ & 93 & $10-240$ & $5 \mathrm{~h}$ & 0.1998 & 3.445 & 0.9772 & 1.252 & 0.5192 & 0.7363 & [14] \\
\hline China (Zhejiang) & $0.8-1.43$ & 48 & $10-4000$ & $24 \mathrm{~h}$ & 0.009 & 14.265 & 0.993 & 0.985 & 0.355 & 0.973 & [15] \\
\hline Bulgaria (-) & $0.2-1.0$ & 83 & $50-250$ & $1 \mathrm{~h}$ & 0.063 & 7.85 & 0.998 & 1.88 & 0.27 & 0.899 & [16] \\
\hline China (Zhejiang) & $<0.074$ & - & $50-250$ & $8 \mathrm{~h}$ & 0.074 & 11.202 & 0.968 & 2.71 & 0.28 & 0.982 & [17] \\
\hline Turkey (Sivas) & $<0.075$ & - & $20-400$ & - & 0.0548 & 9.64 & 0.965 & 0.93 & 0.488 & 0.965 & [18] \\
\hline Turkey (-) & $1.0-1.4$ & 85 & $25-150$ & - & 0.029 & 8.121 & 0.927 & 0.517 & 0.612 & 0.952 & [19] \\
\hline Turkey (Dogantepe) & $1.0-2.0$ & 45 & $8.8-885$ & $20 \mathrm{~min}$ & 0.018 & 25.77 & 0.9851 & 2.23 & 0.38 & 0.9847 & [20] \\
\hline
\end{tabular}




\section{Materials and Methods}

\subsection{Zeolite Samples, Solutions, and Chemicals}

Three different Slovakian CLIs were obtained from the suppliers Zeocem (Bystré, Slovakia) and Labradorit GmbH (Berlin, Germany). According to the suppliers, the CLIs were ground and sieved to a particle size smaller than $200 \mu \mathrm{m}$ (Micro 200) or $20 \mu \mathrm{m}$ (EcoZeo 20 and CCP 20 (CCP = Carpathian clinoptilolite powder)). The CLIs were dried at $105^{\circ} \mathrm{C}$ for $24 \mathrm{~h}$ before use. No other pretreatment was conducted. The composition of the examined CLIs is listed in Table 2.

For all experiments, an ammonium solution with a concentration of $1000 \mathrm{mg} \mathrm{NH} \mathrm{NH}_{4} \mathrm{~N} / \mathrm{L}$ was prepared from ammonium chloride with an arbitrary $\mathrm{pH}$ of 5.3. $\mathrm{NH}_{4} \mathrm{Cl}$ (p.a.), $\mathrm{NH}_{4} \mathrm{Ac}$ (ammonium acetate, p.a.), $\mathrm{KCl}$ (р.a.), $\mathrm{NaOH}$ (p.a.), $\mathrm{HF}(47-51 \%$, p.a.), $\mathrm{HCl}(32 \%$, p.a.), and ethanol (99.5\%) were obtained from VWR International (Radnor, Pennsylvania, USA). $\mathrm{HNO}_{3}(67-69 \%$, p.a.) was obtained from Bernd Kraft GmbH (Duisburg, Germany).

Table 2. Relative atomic percentages (weight/weight) of examined CLIs.

\begin{tabular}{cccc}
\hline Supplier & Labradorit & Zeocem & Zeocem \\
\hline CLI & CCP 20 & Micro 200 & EcoZeo 20 \\
Particle Size & $0-20 \mu \mathrm{m}$ & $0-200 \mu \mathrm{m}$ & $0-20 \mu \mathrm{m}$ \\
\hline Element & $\%[\mathrm{wt} / \mathrm{wt}]$ & $\%[\mathrm{wt} / \mathrm{wt}]$ & $\%[\mathrm{wt} / \mathrm{wt}]$ \\
$\mathrm{Al}$ & $5.4 \%$ & $5.3 \%$ & $5.3 \%$ \\
$\mathrm{Ca}$ & $1.6 \%$ & $1.8 \%$ & $1.8 \%$ \\
$\mathrm{Mg}$ & $0.3 \%$ & $0.3 \%$ & $0.3 \%$ \\
$\mathrm{Na}$ & $0.4 \%$ & $0.1 \%$ & $0.1 \%$ \\
$\mathrm{~K}$ & $2.0 \%$ & $1.9 \%$ & $1.9 \%$ \\
$\mathrm{Si}$ & $35.5 \%$ & $34.7 \%$ & $34.7 \%$ \\
$\mathrm{~Pb}$ & $0.001 \%$ & $0.001 \%$ & $0.001 \%$ \\
$\mathrm{Ba}$ & $0.08 \%$ & $0.08 \%$ & $0.08 \%$ \\
$\mathrm{Fe}$ & $1.0 \%$ & $0.9 \%$ & $0.9 \%$ \\
$\mathrm{Ti}$ & $0.1 \%$ & $0.1 \%$ & $0.1 \%$ \\
\hline
\end{tabular}

Below detection limit: $\mathrm{Cr}, \mathrm{Ni}, \mathrm{As}, \mathrm{Rb}, \mathrm{Cd}, \mathrm{Cs}, \mathrm{Ba}, \mathrm{Hg}$, Tl. In total, the mass does not add up to $100 \%$, since the element oxygen is not detected by the analysis method.

\subsection{Experimental Design}

\subsubsection{Cation Exchange Capacity (CEC)}

To determine the amount of interchangeable cations, $1 \mathrm{~g}$ of dried CLI was weighed into centrifuge tubes and mixed with $30 \mathrm{~mL}$ of $1 \mathrm{M} \mathrm{NH}_{4}$ Ac solution for 30 minutes in a rotator (uniROTATOR2, LLG Labware, Meckenheim, Germany) at $120 \mathrm{rpm}$ and $22{ }^{\circ} \mathrm{C}$ (no pH adjustment). After centrifugation at $4000 \mathrm{rpm}$ for $10 \mathrm{~min}$, the supernatant was decanted and collected. The remaining CLI in the centrifuge tube was again mixed with fresh $30 \mathrm{~mL}$ of $1 \mathrm{M} \mathrm{NH}_{4}$ Ac solution and treated according to the described procedure. In total, the procedure was carried out three times and the arising three supernatants were mixed and collected. Subsequently, the mixtures were analyzed for desorbed alkali and alkaline earth metals, which correspond to the cations exchanged. Afterwards, the CLI was washed with $30 \mathrm{~mL} 80 \%$ ethanol solution three times to remove unadsorbed ammonium, following the same procedure until no ammonium in the supernatant was detected. The loaded CLI was then regenerated three times with $30 \mathrm{~mL} 1 \mathrm{M} \mathrm{KCl}$ solution using the same procedure. The resulting supernatant was collected and analyzed for ammonium. The cation exchange capacity corresponds to the cations that were exchanged by ammonium. 


\subsubsection{Isoelectric State of CLI and $\mathrm{pH}$-Dependent Adsorption}

The $\mathrm{NH} 4 \mathrm{Cl}$ solution investigated was previously adjusted to $\mathrm{pH}$ values ranging from 2 to 12 by $\mathrm{HCl}$ or $\mathrm{NaOH}$. The specific sorbent mass was fixed at a ratio of $0.1 \mathrm{~g}$ CLI per mg NH4-N. Sorbent $(20 \mathrm{~g})$ and solution $(200 \mathrm{~mL})$ were stirred for $20 \mathrm{~h}$ on a magnetic stirrer $(400 \mathrm{rpm})$ at room temperature $\left(22^{\circ} \mathrm{C}\right)$ in closed bottles, membrane-filtered $(0.45 \mu \mathrm{m}$ pore size $)$, and subsequently the $\mathrm{pH}$ value as well as the ammonium concentration were determined. The initial $\mathrm{pH}$ values of the solutions were compared with those of the filtrates. The isoelectric state is the point at which both $\mathrm{pH}$ values are identical.

\subsubsection{Isothermal Adsorption}

The aim of the investigations was to determine the influence of temperature on CLI loading. Since wastewater with very high ammonium concentrations, e.g., sludge water, originates from the digestion tower operated mostly at a mesophilic temperature, the temperature of $34{ }^{\circ} \mathrm{C}$ (considering small heat losses) was chosen as the upper temperature limit. In addition, temperatures of $22^{\circ} \mathrm{C}$ (room temperature) and $10^{\circ} \mathrm{C}$ were tested.

Since in real wastewater the concentration of ammonium $\mathrm{c}_{0}(\mathrm{mg} / \mathrm{L})$ cannot be changed without influencing its ionic composition, the sorbent mass $\mathrm{m}(\mathrm{g})$ was varied. Thus, different quantities ranging from 2 to $48 \mathrm{~g}$ sorbent were mixed with $200 \mathrm{~mL}$ adsorption solution $\mathrm{V}_{\mathrm{p}}(\mathrm{mL})$ and stirred at a constant temperature $\left(10{ }^{\circ} \mathrm{C}, 22{ }^{\circ} \mathrm{C}\right.$, and $\left.34{ }^{\circ} \mathrm{C}\right)$ on a magnetic stirrer at $400 \mathrm{rpm}$. After $20 \mathrm{~h}$, the residual ammonium concentration $\mathrm{c}_{\mathrm{eq}}(\mathrm{mg} / \mathrm{L})$ as well as $\mathrm{pH}$ in the filtrate were determined. Since the $\mathrm{pH}$ barely varied between the different dosages and a competition adsorption by $\mathrm{Na}^{+}$or $\mathrm{H}_{3} \mathrm{O}^{+}$cations as well as a dilution due to the $\mathrm{pH}$ adjustment was to be avoided, a $\mathrm{pH}$ correction was not conducted. One experimental approach without sorbent for each examined $\mathrm{pH}$ was used to determine unwanted ammonium elimination, e.g., by stripping or adsorption onto parts of the glass apparatus. The ammonium concentration in the filtrate of that approach is expressed as $\mathrm{c}_{B}(\mathrm{mg} / \mathrm{L})$. The loading $\mathrm{q}_{\mathrm{eq}}(\mathrm{mg} / \mathrm{g})$ of the sorbent mass was determined by Equation (1).

$$
\mathrm{q}_{\mathrm{eq}}=\frac{\left(\mathrm{c}_{0}-\left(\mathrm{c}_{0}-\mathrm{c}_{\mathrm{B}}\right)-\mathrm{c}_{\mathrm{eq}}\right) \times\left(\frac{\mathrm{V}_{\mathrm{p}}}{1000}\right)}{\mathrm{m}}
$$

\subsubsection{Adsorption Kinetics}

CLI was mixed with the $\mathrm{NH}_{4} \mathrm{Cl}$ solution $(1.5 \mathrm{~L})$ at a specific sorbent ratio of $0.1 \mathrm{~g}$ CLI per $\mathrm{mg}$ $\mathrm{NH}_{4}-\mathrm{N}$ on a magnetic stirrer at $22{ }^{\circ} \mathrm{C}$. At periodic intervals, an aliquot $(10 \mathrm{~mL})$ was taken and immediately membrane-filtered $(0.45 \mu \mathrm{m}$ pore size $)$ to prevent further contact between sorbent and sample. Subsequently, the ammonium concentration was measured in the filtrate and the time-dependent loading of the sorbent $\mathrm{q}_{\mathrm{t}}(\mathrm{mg} / \mathrm{g})$ was calculated. Since it is known from published studies that the adsorption kinetics strongly depend on the stirring speed $[15,21,22]$, a high rotation frequency of $800 \mathrm{rpm}$ was chosen to determine the maximum possible adsorption kinetic values. During the test, due to sampling, the total volume was continuously reduced. However, it can be assumed that during the sampling no change in the ratio of the sorbent mass to the volume of the adsorption solution occurred due to the homogeneously mixed conditions.

The arbitrary $\mathrm{pH}$ of the $\mathrm{NH}_{4} \mathrm{Cl}$-soution was 5.3. As a consequence of the contact with zeolite, the $\mathrm{pH}$ value immediately rose to 6.6 and increased to 7.1 with increasing contact time.

\subsection{Adsorption Models}

\subsubsection{Freundlich Model}

The Freundlich model ([23] in [24]) is an empirical approach to describe the equilibrium of sorbent and sorbate. It describes the nonideal, reversible adsorption on a heterogeneous sorbent, whereby less adsorption can be achieved with increasing loading. However, it is not possible to calculate a complete loading, as the sorbent sites can be occupied in several layers. According to Freundlich, the loading 
of the sorbent $\mathrm{q}_{\mathrm{eq}, \mathrm{F}}(\mathrm{mg} / \mathrm{g})$ can be calculated by exponentiation of the corresponding equilibrium concentration $\mathrm{c}_{\mathrm{eq}}(\mathrm{mg} / \mathrm{L})$ with the factor $1 / \mathrm{n}(-)$, as described by Equation (2).

$$
\mathrm{q}_{\mathrm{eq}, \mathrm{F}}=\mathrm{K}_{\mathrm{F}} \times \mathrm{c}_{\mathrm{eq}}{ }^{\frac{1}{n}}
$$

Calculation methods for determining the constants $\mathrm{K}_{\mathrm{F}}$ and $1 / \mathrm{n}$ with the help of nonlinear regression or linearization are given, e.g., by Ho et al. [24]. In this study, the linearization is done by plotting $\log \mathrm{q}_{\mathrm{eq}}$ versus $\log \mathrm{c}_{\mathrm{eq}}$. The gradient of the graph corresponds to $\mathrm{n}$, while the tenth power of the intercept represents $\mathrm{K}_{\mathrm{F}}$.

\subsubsection{Langmuir Model}

The adsorption model of Langmuir [25] assumes that the sorbent is loaded with a monomolecular layer of adsorbate. Accordingly, the properties of the sorbent sites are identical and equivalent, so that a determination of the maximum adsorption capacity is possible. The loading of sorbent is calculated according to Equation (3), where $\mathrm{K}_{\mathrm{L}}(\mathrm{L} / \mathrm{mg})$ is the Langmuir constant and $\mathrm{q}_{\max }(\mathrm{mg} / \mathrm{g})$ the maximum capacity.

$$
\mathrm{q}_{\mathrm{eq}, \mathrm{L}}=\frac{\mathrm{q}_{\mathrm{max}} \mathrm{K}_{\mathrm{L}} \mathrm{C}_{\mathrm{eq}}}{1+\mathrm{K}_{\mathrm{L}} \mathrm{C}_{\mathrm{eq}}}
$$

The constants can either be calculated from linear or nonlinear regression based on measurement results. By plotting $c_{\text {eq }} / \mathrm{q}_{\text {eq }}$ vs. $c_{\text {eq }}, 1 / \mathrm{q}_{\text {eq }}$ vs. $1 / c_{\text {eq }}, \mathrm{q}_{\text {eq }}$ vs. $\mathrm{q}_{\text {eq }} / \mathrm{c}_{\mathrm{eq}}$, or $\mathrm{q}_{\mathrm{eq}} / \mathrm{c}_{\mathrm{eq}} \mathrm{vs.} \mathrm{q}_{\mathrm{eq}}$, a linear relationship for Equation (3) can be deduced [26]. Table 3 lists the four possible linear forms for determining Langmuir constants. In this study, only the type of isotherm with the highest coefficient of determination $r^{2}$ is listed. The correlation coefficient $r^{2}$ of the nonlinear form of the Langmuir isotherm and the experimentally determined loads $\mathrm{q}_{\mathrm{eq}}$ and the arithmetical average loads $\overline{\mathrm{q}_{\mathrm{eq}}}$ was calculated according to Equation (4).

$$
\mathrm{r}^{2}=\frac{\sum\left(\mathrm{q}_{\mathrm{eq}, \mathrm{L}}-\overline{\mathrm{q}_{\mathrm{eq}}}\right)^{2}}{\sum\left(\mathrm{q}_{\mathrm{eq}, \mathrm{L}}-\overline{\mathrm{q}_{\mathrm{eq}}}\right)^{2}+\sum\left(\mathrm{q}_{\mathrm{eq}, \mathrm{L}}-\mathrm{q}_{\mathrm{eq}}\right)^{2}}
$$

Table 3. Linear forms of the Langmuir isotherm (according to [27]).

\begin{tabular}{ccccc}
\hline Type & \multicolumn{1}{c}{ Linear form } & Plot & $\mathbf{K}_{\mathrm{L}}$ & $\mathbf{q}_{\text {max }}$ \\
\hline I & $\frac{\mathrm{c}_{\mathrm{eq}}}{\mathrm{q}_{\mathrm{eq}}}=\frac{1}{\mathrm{q}_{\max } \mathrm{K}_{\mathrm{L}}}+\frac{\mathrm{c}_{\mathrm{eq}}}{\mathrm{q}_{\mathrm{max}}}$ & $\frac{\mathrm{c}_{\mathrm{eq}}}{\mathrm{q}_{\mathrm{eq}}}$ vs. $\mathrm{c}_{\mathrm{eq}}$ & slope/intercept & $1 /$ slope \\
II & $\frac{1}{\mathrm{q}_{\mathrm{eq}}}=\left[\frac{1}{\mathrm{q}_{\max } \mathrm{K}_{\mathrm{L}}}\right] \frac{1}{\mathrm{c}_{\mathrm{eq}}}+\frac{1}{\mathrm{q}_{\max }}$ & $\frac{1}{\mathrm{q}_{\mathrm{eq}}}$ vs. $\frac{1}{\mathrm{c}_{\mathrm{eq}}}$ & intercept/slope & $1 /$ intercept \\
III & $\mathrm{q}_{\mathrm{eq}}=\mathrm{q}_{\max }-\left[\frac{1}{\mathrm{~K}_{\mathrm{L}}}\right] \frac{\mathrm{q}_{\mathrm{eq}}}{\mathrm{c}_{\mathrm{eq}}}$ & $\mathrm{q}_{\mathrm{eq}}$ vs. $\frac{\mathrm{q}_{\mathrm{eq}}}{\mathrm{c}_{\mathrm{eq}}}$ & $1 /$ slope & intercept \\
IV & $\frac{\mathrm{q}_{\mathrm{eq}}}{\mathrm{c}_{\mathrm{eq}}}=\mathrm{q}_{\max } \mathrm{K}_{\mathrm{L}}-\mathrm{c}_{\mathrm{eq}} \mathrm{K}_{\mathrm{L}}$ & $\frac{\mathrm{q}_{\mathrm{eq}}}{\mathrm{c}_{\mathrm{eq}}}$ vs. $\mathrm{q}_{\mathrm{eq}}$ & $(-1)$ slope & intercept/slope \\
\hline
\end{tabular}

\subsubsection{Temkin Model}

The isothermal loading of sorbents according to Temkin ([28] in [29]) is extended by the temperature parameter. Accordingly, the adsorption enthalpy is linearly proportional to the loading on the sorbent [30]. The form of the isotherm used in this work is taken from Ho et al. [24] (Equation (5)), where $R$ is the universal gas constant $(8.314459 \mathrm{~J} /(\mathrm{mol} \mathrm{K}))$, $\mathrm{T}$ the temperature $(\mathrm{K}), \mathrm{b}_{\mathrm{T}}(1 / \mathrm{mol})$, and $\mathrm{A}_{\mathrm{T}}$ $(\mathrm{L} / \mathrm{mg})$ the Temkin isothermal constants.

$$
\mathrm{q}_{\mathrm{eq}, \mathrm{T}}=\frac{\mathrm{RT}}{\mathrm{b}_{\mathrm{T}}} \ln \left(\mathrm{A}_{\mathrm{T}} \mathrm{C}_{\mathrm{eq}}\right)
$$

The linearized form of the Temkin isotherm is shown in Equation (6). 


$$
\mathrm{q}_{\mathrm{eq}, \mathrm{T}}=\frac{\mathrm{RT}}{\mathrm{b}_{\mathrm{T}}} \ln \left(\mathrm{A}_{\mathrm{T}}\right)+\frac{\mathrm{RT}}{\mathrm{b}_{\mathrm{T}}} \ln \left(\mathrm{c}_{\mathrm{eq}}\right)
$$

For the determination of $b_{T}$ and $A_{T}$, ln ceq vs. $q_{e q}$ is plotted; the slope represents the term $R T / b_{T}$, the intersection with the ordinate the term $\mathrm{RT} \ln \left(\mathrm{A}_{\mathrm{T}}\right) / \mathrm{b}_{\mathrm{T}}$.

\subsubsection{Thermodynamic Calculations}

During the adsorption process, thermodynamic effects, shown in the form of energy adsorption or release, i.e., a temperature increase or decrease, can be observed. The standard free energy $\Delta \mathrm{G}^{0}$ $(\mathrm{kJ} / \mathrm{mol})$ can be calculated according to the following Equation (7)

$$
\Delta \mathrm{G}^{0}=-\mathrm{RT} \ln \left(\mathrm{K}_{\mathrm{d}}\right)
$$

where $K_{d}$ is the thermodynamic equilibrium constant, here the Freundlich constant $(\mathrm{L} / \mathrm{g})$. According to Milonjic [31], it should be noted that $K_{d}$ must be dimensionless. Therefore, the use of the temperature-dependent equilibrium constant $\mathrm{K}_{\mathrm{F}}$ must be corrected by a factor of $1000 \mathrm{~g} / \mathrm{L}$ (density of water) in its dimensionless form. The relationship of the other thermodynamic parameters such as change in enthalpy $\Delta \mathrm{H}^{0}(\mathrm{~kJ} / \mathrm{mol})$ and change in standard entropy $\Delta \mathrm{S}^{0}(\mathrm{~J} /(\mathrm{mol} \mathrm{K}))$ can be derived by means of the Gibbs-Helmholtz equation (8).

$$
\Delta \mathrm{G}^{0}=\Delta \mathrm{H}^{0}-\mathrm{T} \Delta \mathrm{S}^{0}
$$

A linear correlation, which enables the determination of the change in standard entropy $\Delta S^{0}$ and free standard enthalpy $\Delta \mathrm{H}^{0}$, is shown in a diagram in which the logarithmic equilibrium constant $\mathrm{K}_{\mathrm{d}}$ is plotted against the reciprocal value of the temperature 1/T (Van't-Hoff diagram). Here, the gradient corresponds to the quotient of the negative change in the free standard enthalpy $\Delta \mathrm{H}^{0}$ and the universal gas constant R. Furthermore, the quotient of the change of the free molar standard entropy $\Delta S^{0}$ and the universal gas constant can be read from the axis section.

Endothermic adsorption is described by a positive value of $\Delta \mathrm{H}^{0}$, meaning energy is absorbed by the adsorption process. A negative value indicates exothermic adsorption, meaning energy is being released. A spontaneous (exergonic) adsorption is described by negative values of $\Delta G^{0}$, while negative values of $\Delta S^{0}$ indicate a random adsorption behavior.

\subsection{Kinetic Models}

\subsubsection{Intraparticle Diffusion}

According to Weber and Morris ([32] in [33]), a mathematical description of the diffusion process is provided by the intraparticle diffusion model (ID), which constitutes a correlation between the loading rate $\mathrm{k}_{\mathrm{ID}}\left(\mathrm{mg} /\left(\mathrm{g} \mathrm{min}{ }^{0.5}\right)\right)$ and the square root of the contact time $\mathrm{t}(\mathrm{min})$. McKay et al. [34] extend this model by the constant $C(\mathrm{mg} / \mathrm{g})$, which is proportional to the thickness of the boundary layer as well as the initial adsorption by it. The time-dependent loading of the sorbent $\mathrm{q}_{\mathrm{t}, \mathrm{ID}}(\mathrm{mg} / \mathrm{g})$ can be calculated by Equation (9).

$$
\mathrm{q}_{\mathrm{t}, \mathrm{ID}}=\mathrm{k}_{\mathrm{ID}} \mathrm{t}^{0.5}+\mathrm{C}
$$

To determine the loading rate $\mathrm{k}_{\mathrm{ID}}$, $\mathrm{q}_{\mathrm{t}}$ versus $\mathrm{t}^{0.5}$ is plotted. The slope of the resulting graph corresponds to $\mathrm{k}_{\mathrm{ID}}$ while the intersection with the ordinate corresponds to $\mathrm{C}$. Sole intraparticle diffusion occurs when the graph intersects the origin $(C=0)$. If a multistage diffusion process is present, two or more partial lines passing into each other can be approximated to the existing empirical measuring points of $\mathrm{q}_{\mathrm{t}}$. 


\subsubsection{Pseudo-Second-Order}

A mathematical model describing the time-dependent loading of the sorbent is possible with the pseudo-second-order (PSO) model according to Ho and McKay [35]. However, it is not possible to make statements about the prevailing adsorption kinetic processes when using this model. Rather, it employs a macroscopic view of the adsorption process. The model is based on the assumption that the adsorption rate is dependent on the loading of the ion exchange material at a certain point in time and its equilibrium state. Equation (10) shows the PSO in its differential form, i.e., as the differential of the load $\mathrm{q}_{\mathrm{t}}(\mathrm{mg} / \mathrm{g})$ at any time $\mathrm{t}$

$$
\frac{d \mathrm{q}_{\mathrm{t}, \mathrm{PSO}}}{\mathrm{dt}}=\mathrm{k}_{2}\left(\mathrm{q}_{\mathrm{e}}-\mathrm{q}_{\mathrm{t}}\right)^{2}
$$

where $\mathrm{k}_{2}$ is the pseudo-second-order rate $(\mathrm{mg} /(\mathrm{g} \mathrm{min}))$ and $\mathrm{q}_{\mathrm{e}}(\mathrm{mg} / \mathrm{g})$ the load at equilibrium. From the integration of Equation (9) with the boundary conditions $q_{t}=0$ at $t=0$ and $q_{t}=q_{t}$ at $t=t$, four different linear forms of the PSO model can be obtained (Table 4).

Table 4. Linear forms of PSO model (according to [36]).

\begin{tabular}{ccccc}
\hline Type & Linear form & Plot & $\mathbf{k}_{2}$ & $\mathrm{q}_{\mathrm{e}}$ \\
\hline I & $\frac{\mathrm{t}}{\mathrm{q}_{\mathrm{t}}}=\frac{1}{\mathrm{k}_{2} \mathrm{q}_{\mathrm{e}}^{2}}+\frac{\mathrm{t}}{\mathrm{q}_{\mathrm{e}}}$ & $\frac{\mathrm{t}}{\mathrm{q}_{\mathrm{t}}}$ vs. t & ${\text { (slope })^{2} / \text { intercept }}^{2}$ & $1 /$ slope \\
II & $\frac{1}{\mathrm{q}_{\mathrm{t}}}=\left[\frac{1}{\mathrm{k}_{2} \mathrm{q}_{\mathrm{e}}{ }^{2}}\right] \frac{1}{\mathrm{t}}+\frac{1}{\mathrm{q}_{\mathrm{e}}}$ & $\frac{1}{\mathrm{q}_{\mathrm{t}}}$ vs. $\frac{1}{\mathrm{t}}$ & $(\text { intercept })^{2} /$ slope & $1 /$ intercept \\
III & $\mathrm{q}_{\mathrm{t}}=\mathrm{q}_{\mathrm{e}}-\left[\frac{1}{\mathrm{k}_{2} \mathrm{q}_{\mathrm{e}}}\right] \frac{\mathrm{q}_{\mathrm{t}}}{\mathrm{t}}$ & $\mathrm{q}_{\mathrm{t}}$ vs. $\frac{\mathrm{q}_{\mathrm{t}}}{\mathrm{t}}$ & $(-1) /($ slope $\times$ intercept) & intercept \\
IV & $\frac{\mathrm{q}_{\mathrm{t}}}{\mathrm{t}}=\mathrm{k}_{2} \mathrm{q}_{\mathrm{e}}{ }^{2}-\mathrm{k} \mathrm{q}_{\mathrm{e}} \mathrm{q}_{\mathrm{t}}$ & $\frac{\mathrm{q}_{\mathrm{t}}}{\mathrm{t}}$ vs. $\mathrm{q}_{\mathrm{t}}$ & $(\text { slope })^{2} /$ intercept & -intercept/slope \\
\hline
\end{tabular}

In this study, only the type with the highest coefficient of determination $\mathrm{r}^{2}$ (Equation (4)) is listed.

\subsection{Analytical Methods}

Ammonium was measured according to German standard DIN 38406-5 [37]. At a pH of about 12.6, ammonium cations and ammonia contained in the sample react with hypochlorite ions and salicylate ions in the presence of sodium pentacyanonitrosylferrate (2-)(nitroprusside sodium) as a catalyst to form a blue dye. The required hypochlorite ions are formed in the alkaline medium by hydrolysis of the dichloroisocyanuric acid ions. The absorbance of the blue dye at $655 \mathrm{~nm}$ wavelength is linearly proportional to the ammonium concentration.

For determination of $\mathrm{pH}$, probes (SenTix $950+$ Multi 3430) (WTW, Weilheim, Germany) were used.

To determine the chemical elements of the zeolite, 0.3 to $0.5 \mathrm{~g}$ of the CLI were weighed and mixed with $6 \mathrm{~mL} \mathrm{HNO}_{3}(65 \%), 4 \mathrm{~mL} \mathrm{HF}$, and $2 \mathrm{~mL} \mathrm{HCl}$. The mixture was digested by microwave (Start, MLS GmbH, Leutkirch, Germany) with a selected program run of $10 \mathrm{~min}$ at $110{ }^{\circ} \mathrm{C}$, then $5 \mathrm{~min}$ at $140{ }^{\circ} \mathrm{C}$, and finally $9 \mathrm{~min}$ at $190^{\circ} \mathrm{C}$. Together with the cooling phase, the digestion lasted $64 \mathrm{~min}$. Heavy metals were analyzed by inductively coupled plasma mass spectrometry (Nexion 2000, Perkin Elmer, Waltham, MA, USA).

\section{Results and Discussion}

\subsection{Cation Exchange Capacity}

The amount of exchanged cations is given in Table 5. All investigated CLIs adsorbed an almost equal amount of ammonium (121-137 meq/100g) and desorbed a similar amount of alkali and alkaline earth cations, indicating an electro-neutral ion exchange. In terms of ammonium, CCP 20 adsorbed the largest amount of around 137 meq/100g, while Micro 200 and EcoZeo 20 adsorbed 125 and $121 \mathrm{meq} / 100 \mathrm{~g}$, respectively. Thus, no correlation to the material size could be found. During the ammonium adsorption, similar equivalent amounts of alkaline earth metal cations were desorbed from all three CLIs (119-139 meq/100g). In all cases, calcium was exchanged with the highest amount 
(63-67 meq/100g), followed by potassium (45-49 meq/100g), while magnesium was exchanged in a similar order of magnitude from all three materials, and the exchange of sodium differed significantly between around 3 and $21 \mathrm{meq} / 100 \mathrm{~g}$.

In the case of CCP 20, the largest amount of ammonium was exchanged for the largest amount of cations. Malekian et al. [38] reported a similar Cation Exchange Capacity (CEC) of 140-165 cmol/ kg (=140-165 meq/100g) for millimeter- and nanometer-sized particles of Iranian zeolite.

Table 5. Adsorbed ammonium and exchanged cations by the investigated CLIs.

\begin{tabular}{ccccccc}
\hline \multirow{2}{*}{ CLI } & \multicolumn{2}{c}{ Adsorbed } & \multicolumn{2}{c}{ Desorbed } & Exchanged Cations \\
\cline { 2 - 7 } & $\mathbf{N H}_{\mathbf{4}}{ }^{+}$ & $\mathbf{K}^{+}$ & $\mathbf{N a}^{+}$ & $\mathbf{C a}^{\mathbf{2 +}}$ & $\mathbf{M g}^{\mathbf{2 +}}$ & $\mathbf{C E C}$ \\
\cline { 2 - 7 } & {$[\mathbf{m e q} / \mathbf{1 0 0 g}]$} & {$[\mathbf{m e q} / \mathbf{1 0 0}]$} & {$[\mathbf{m e q} / \mathbf{1 0 0 g}]$} & {$[\mathbf{m e q} / \mathbf{1 0 0}]$} & {$[\mathbf{m e q} / \mathbf{1 0 0 g}]$} & {$[\mathbf{m e q} / \mathbf{1 0 0 g}]$} \\
\hline CCP 20 & 136.9 & 49.3 & 21.0 & 65.6 & 3.3 & 139.2 \\
Micro 200 & 125.0 & 47.4 & 3.4 & 67.4 & 4.3 & 122.5 \\
EcoZeo 20 & 121.4 & 45.1 & 7.6 & 62.9 & 3.8 & 119.4 \\
\hline
\end{tabular}

\subsection{Isoelectric State and $p H$-Dependent Adsorption}

In Figure 1, the final $\mathrm{pH}$ values of the filtrates are plotted against the $\mathrm{pH}$ values of the $\mathrm{NH}_{4} \mathrm{Cl}$ solution after $\mathrm{pH}$ adjustment. The increase of the $\mathrm{pH}$ values in the range of 2 to 7 can be attributed to the removal of $\mathrm{NH}_{4}{ }^{+}$leaving an increasing amount of $\mathrm{OH}^{-}$, as well as leaching of cations (e.g., $\mathrm{K}^{+}, \mathrm{Na}^{+}, \mathrm{Ca}^{2+}, \mathrm{Mg}^{2+}$ ). At higher $\mathrm{pH}$ values, especially in the alkaline range, no change in the $\mathrm{pH}$ could be observed. This can be attributed to the decrease in adsorption, since uncharged $\mathrm{NH}_{3}$ which occurs at $\mathrm{pH}>9$ cannot be adsorbed by CLI and, therefore, no more cations that influence the $\mathrm{pH}$ can be released.

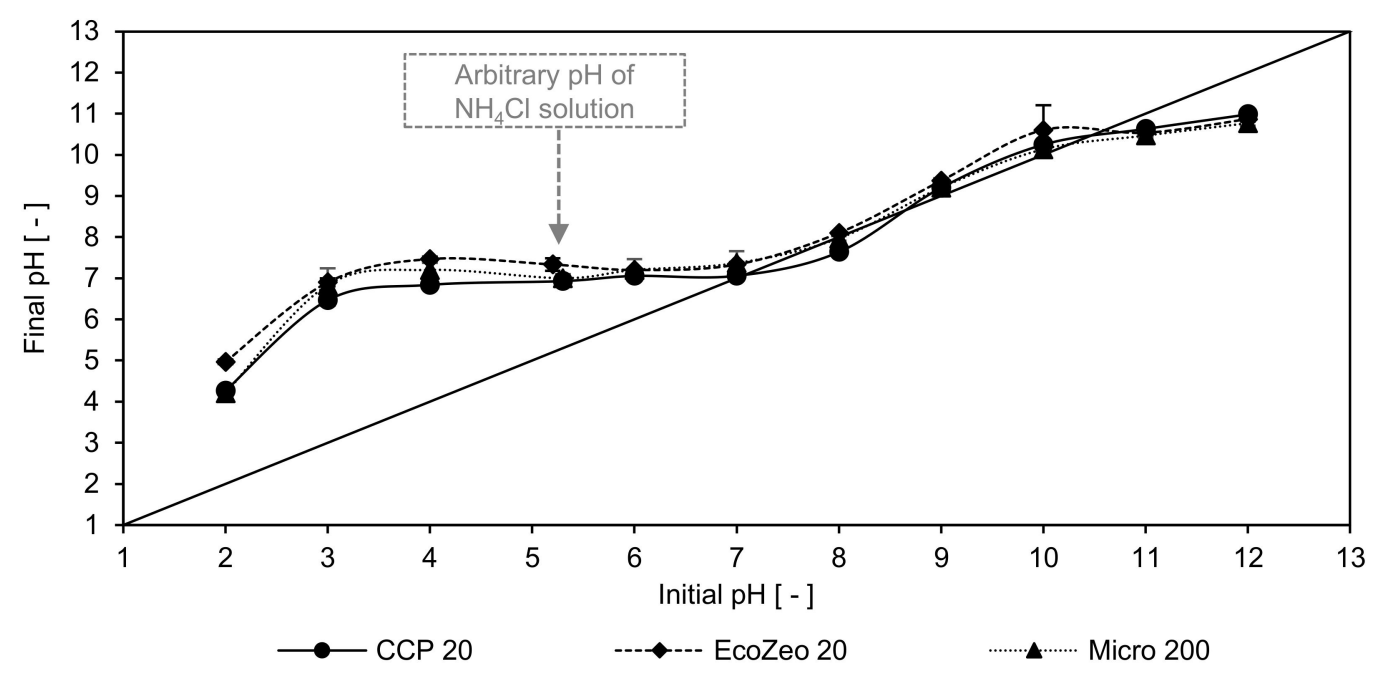

Figure 1. $\mathrm{pH}$ values of the filtrates after $20 \mathrm{~h}$ contact with CCP 20, Micro 200, and EcoZeo 20 ( $c_{0}=1000 \mathrm{mg} \mathrm{NH}_{4}-\mathrm{N} / \mathrm{L}$, sorbent ration $\left.0.1 \mathrm{~g}_{\mathrm{CLI}} / \mathrm{mg}_{\mathrm{NH} 4-\mathrm{N}}\right)$ as a function of the initial $\mathrm{pH}$ values (adjusted $\mathrm{pH}$ values of the solution before contact with CLI).

The isoelectric state of CCP 20 was determined between pH 7.9 and 10.5, while EcoZeo 20 and Micro 200 had their equilibrium between $\mathrm{pH} 8$ and 10.5. Compared to the results of Zhang and Bi [39], who determined an isoeletric state of 5.3 for natural CLI, the CLIs of this study had an increased negative charge, resulting in a higher isoeletric state. An even lower isoeletric state of 4.5 was reported by Guaya et al. [10] who investigated modified Slovakian CLI. However, the authors observed that at a $\mathrm{pH}$ of 9 the maximum ammonium is adsorbed. 
In Figure 2, the ammonium elimination by CCP 20, Micro 200, and EcoZeo 20 is depicted as a function of $\mathrm{pH}$. The standard deviation around the mean value is represented by black bars. Additionally, the $\mathrm{pH}$-dependent level of speciation $\alpha$ of ammonium is shown by the secondary axis.

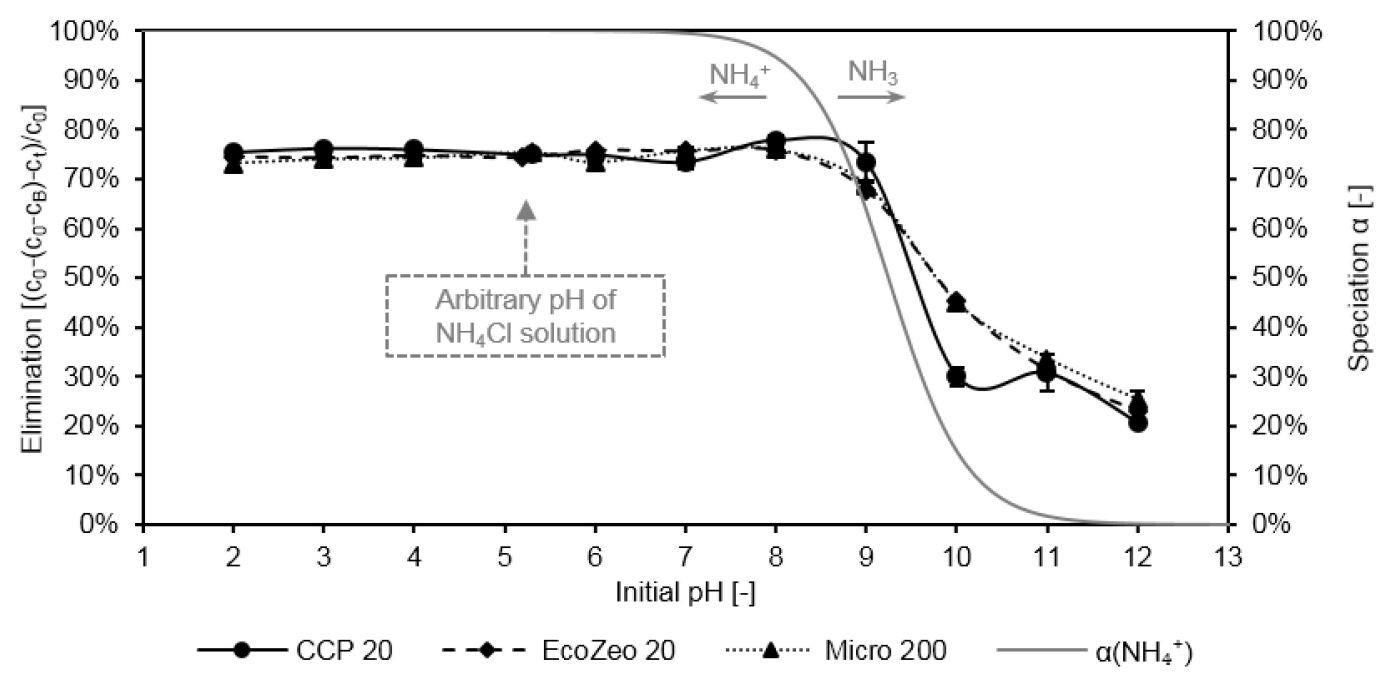

Figure 2. Elimination of ammonium by CCP 20, Micro 200, and EcoZeo 20 after $20 \mathrm{~h}$ contact time from $\mathrm{NH}_{4} \mathrm{Cl}$ solution $\left(\mathrm{c}_{0}=1000 \mathrm{mg} \mathrm{NH} 4-\mathrm{N} / \mathrm{L}\right.$, sorbent ration $\left.0.1 \mathrm{~g}_{\mathrm{CLI}} / \mathrm{mg}_{\mathrm{NH} 4-\mathrm{N}}\right)$ as well as speciation $\alpha$ of ammonium as a function of $\mathrm{pH}$.

All three evaluated CLIs achieved a high elimination in a $\mathrm{pH}$ range from 2 to 8 . In this $\mathrm{pH}$ range, the loading of the sorbents was $\sim 8 \mathrm{mg} \mathrm{NH}_{4}-\mathrm{N} / \mathrm{g}$ (loading not shown in the figure). The arbitrary $\mathrm{pH}$ value of the $\mathrm{NH}_{4} \mathrm{Cl}$ solution is indicated in the figure and amounted to 5.3. With $\mathrm{pH}$ values higher than 9, a significant decrease of elimination could be observed for all CLIs. CCP 20 eliminated $73 \%$ at $\mathrm{pH} 9$, whereas at $\mathrm{pH} 10$ only $30 \%$ of ammonium were removed. Within the same $\mathrm{pH}$ range, elimination by Micro 200 and EcoZeo 20 decreased from $69 \%$ to $45 \%$. At higher $\mathrm{pH}$ values, with all three sorbents only a low elimination of $20 \%$ was achieved.

These observations are consistent with the results published by Li et al. [40] and Guo et al. [41]. The authors investigated the elimination of ammonium by CLI from China and USA and stated that there is no change in the elimination or loading in a pH range of 5 or 6 to 9 . However, with other zeolites, specific $\mathrm{pH}$ values were also found at which maximum elimination extents were achieved ( $\mathrm{pH}$ 8: [42]; $\mathrm{pH} 7$ : [11,14,43]; $\mathrm{pH}$ 6: [13,16,44]; $\mathrm{pH} 4$ : [20]). The decrease in elimination of ammonium was in the same $\mathrm{pH}$ range where ammonium dissociates to uncharged ammonia, which was, thus, no longer available for ion exchange. This finding was also shared by Alshameri et al. [42], who also attributed the decrease in elimination at high $\mathrm{pH}$ to the dissociation of ammonium.

\subsection{Isothermal Adsorption}

Figure 3 shows the equilibrium concentration $c_{\mathrm{eq}}$ and the associated loading of the CLI $\mathrm{q}_{\mathrm{eq}}$ after $20 \mathrm{~h}$ contact time of the ammonium solution at different temperatures. The lines represent the Freundlich isotherm, of which the coefficients of determination were the highest of all the isotherm models (Freundlich, Langmuir, Temkin) tested. From the high correlation with the Freundlich isotherm it can be deduced that CLI has a heterogeneous surface which allows a nonideal adsorption. With increasing load of the CLI, less adsorption of ammonium can be achieved. Table 6 lists the coefficients of the isothermal fit according to Freundlich, Langmuir, and Temkin as well as the coefficients of determination. The final $\mathrm{pH}$ was found to be between 6.4 and 7.3 whereby the latter value was reached with the largest amount of CLI.

Unaffected by temperature, CLI had a low $\mathrm{q}_{\mathrm{eq}}$ when a low $\mathrm{c}_{\mathrm{eq}}$ remained in the solution. At a temperature of $34^{\circ} \mathrm{C}(307 \mathrm{~K})$, all CLIs achieved the highest loading. The highest loading of $\mathrm{q}_{\mathrm{eq}}=18.8 \mathrm{mg} / \mathrm{g}$ was achieved 
with CCP 20 and Micro 200, followed by EcoZeo 20 with $\mathrm{q}_{\mathrm{eq}}=16.3 \mathrm{mg} / \mathrm{g}$. Due to higher temperature, there is a lower viscosity of the solution. As a result, the $\mathrm{NH}_{4}{ }^{+}$cations can penetrate deeper into the lattice, resulting in higher loading of the CLI.

An increase in adsorption capacity with higher temperatures was also reported by Alshameri et al. [14] and Tosun [45]. The authors observed a maximum adsorption capacity of $9.794 \mathrm{mg} / \mathrm{g}$ at $318 \mathrm{~K}$ (investigated range: $298-318 \mathrm{~K}$ ) and $16.305 \mathrm{mg} / \mathrm{g}$ at $313 \mathrm{~K}$ (investigated range: 283-313 K), respectively. However, Gunay [46] reported that with their zeolite used at $308 \mathrm{~K}$, the highest adsorption capacity (q $=15.419 \mathrm{mg} / \mathrm{g}$ ) was achieved and higher temperatures (investigated range: 296-343 K) led to a decrease in adsorption. Although the results show a large variation with regard to the maximum ammonium adsorption at the temperatures examined, it can nevertheless be seen that in the range of $308-318 \mathrm{~K}$, the different CLIs adsorb the most ammonium.

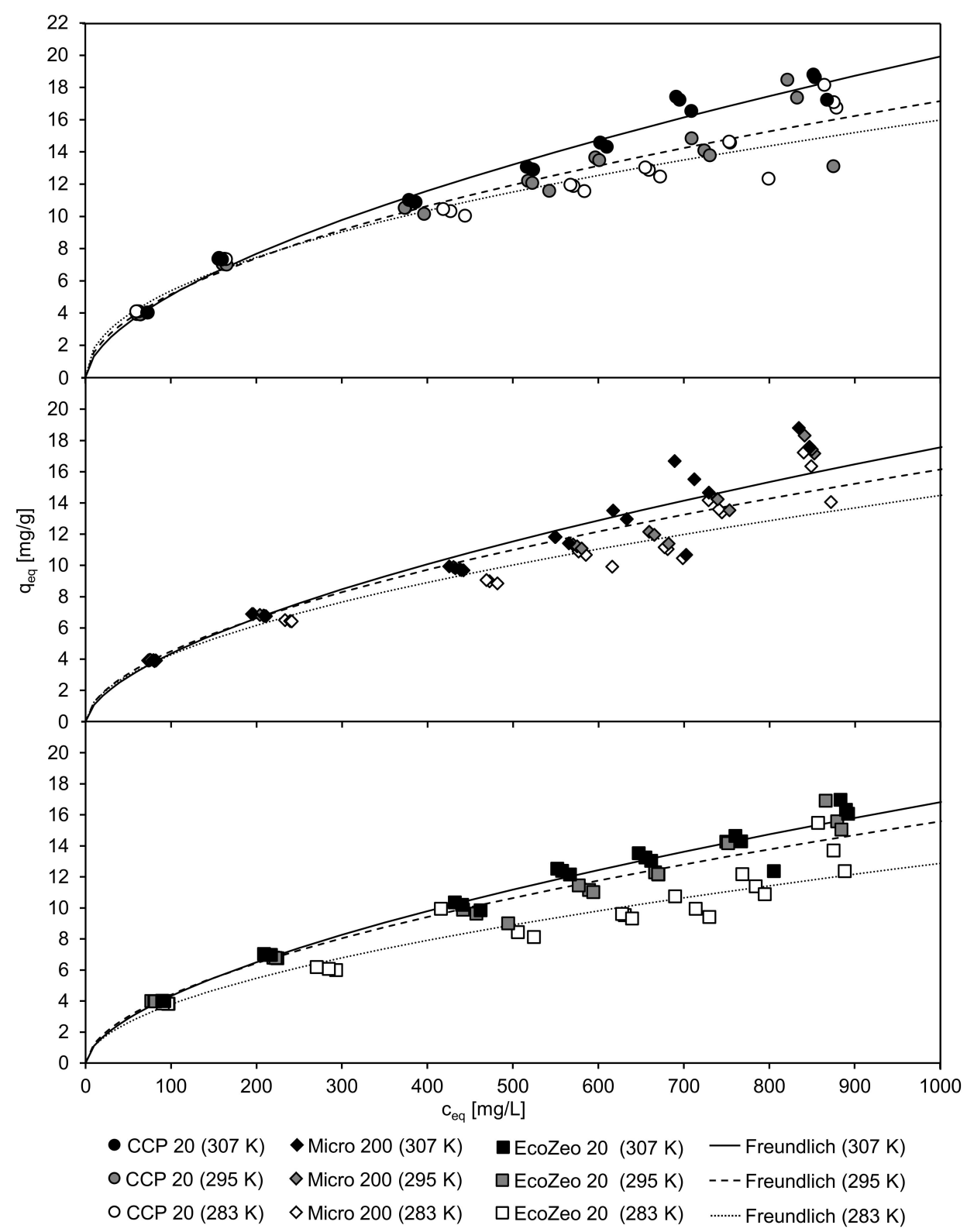

Figure 3. Equilibrium loading $\mathrm{q}_{\mathrm{eq}}$ and equilibrium concentration $\mathrm{c}_{\mathrm{eq}}$ as well as the fit according to the Freundlich model of CCP 20, Micro 200, and EcoZeo 20 after $20 \mathrm{~h}$ contact time with ammonium solution ( $\mathrm{c}_{0}=1000 \mathrm{mg} \mathrm{NH}_{4}-\mathrm{N} / \mathrm{L}, \mathrm{pH}_{\text {Start }} 5.3, \mathrm{pH}_{\text {End }}$ 6.5-7.3) at different temperatures. 
Table 6. Coefficients of the isothermal adaptation according to Freundlich of CCP 20, Micro 200, and EcoZeo 20 after $20 \mathrm{~h}$ contact time with ammonium solution $\left(\mathrm{c}_{0}=1000 \mathrm{mg} \mathrm{NH}_{4}-\mathrm{N} / \mathrm{L}, \mathrm{pH}_{\text {Start }} 5.3\right.$, $\mathrm{pH}_{\text {End }}$ 6.5-7.3).

\begin{tabular}{|c|c|c|c|c|c|c|c|c|c|c|}
\hline \multirow{3}{*}{ CLI } & \multirow{2}{*}{$\begin{array}{c}\text { Temperature } \\
\mathrm{T}\end{array}$} & \multicolumn{3}{|c|}{ Freundlich } & \multicolumn{3}{|c|}{ Langmuir } & \multicolumn{3}{|c|}{ Temkin } \\
\hline & & $\mathrm{K}_{\mathrm{F}}$ & $1 / n$ & $\mathrm{r}^{2}$ & $\mathrm{~K}_{\mathrm{L}}$ & $q_{\max }$ & $\mathbf{r}^{2}$ & $\mathbf{A}_{\mathrm{T}}$ & $\mathbf{b}_{\mathrm{T}}$ & $\mathbf{r}^{2}$ \\
\hline & {$[\mathrm{K}]$} & {$[\mathrm{L} / \mathrm{g}]$} & {$[-]$} & {$[-]$} & {$[\mathrm{L} / \mathrm{mg}]$} & {$[\mathrm{mg} / \mathrm{g}]$} & {$[-]$} & {$[\mathrm{L} / \mathrm{mg}]$} & [J g/(mg mol)] & {$[-]$} \\
\hline \multirow{3}{*}{ ССР 20} & 283 & 0.581 & 0.483 & 0.9239 & 0.003 & 19.90 & 0.5478 & 0.0371 & 584 & 0.8839 \\
\hline & 295 & 0.438 & 0.536 & 0.9349 & 0.003 & 21.58 & 0.5581 & 0.0311 & 524 & 0.9039 \\
\hline & 307 & 0.331 & 0.594 & 0.9821 & 0.002 & 26.71 & 0.5840 & 0.0244 & 441 & 0.9450 \\
\hline \multirow{3}{*}{ Micro 200} & 283 & 0.352 & 0.541 & 0.8584 & 0.002 & 21.24 & 0.5764 & 0.0245 & 568 & 0.8058 \\
\hline & 295 & 0.337 & 0.562 & 0.9043 & 0.002 & 23.11 & 0.5805 & 0.0236 & 513 & 0.8483 \\
\hline & 307 & 0.260 & 0.612 & 0.9004 & 0.002 & 26.58 & 0.6037 & 0.0203 & 476 & 0.8442 \\
\hline \multirow{3}{*}{ EcoZeo 20} & 283 & 0.325 & 0.532 & 0.8547 & 0.002 & 18.23 & 0.5619 & 0.0229 & 632 & 0.8159 \\
\hline & 295 & 0.343 & 0.553 & 0.9533 & 0.002 & 22.15 & 0.5770 & 0.0241 & 538 & 0.8939 \\
\hline & 307 & 0.278 & 0.595 & 0.9698 & 0.002 & 23.87 & 0.5779 & 0.0207 & 500 & 0.9391 \\
\hline
\end{tabular}

\subsection{Thermodynamic Properties}

In Table 7, the coefficients of isothermal adaptation and the determined thermodynamic state variables, free enthalpy of reaction, free standard enthalpy, and molar standard entropy, are shown.

Table 7. Thermodynamic properties of CCP 20, Micro 200, and EcoZeo 20 after $20 \mathrm{~h}$ contact time with ammonium solution ( $\mathrm{c}_{0}=1000 \mathrm{mg} \mathrm{NH}_{4}-\mathrm{N} / \mathrm{L}, \mathrm{pH}_{\text {Start }}$ 5.3, $\mathrm{pH}_{\text {End }}$ 6.5-7.3).

\begin{tabular}{ccccc}
\hline \multirow{2}{*}{ CLI } & Temperature & Free Reaction Enthalpy & Free Standard Enthalpy & Molar Standard Entropy \\
\cline { 2 - 5 } & $\mathbf{T}$ & $\boldsymbol{\Delta G}^{\mathbf{0}}$ & $\boldsymbol{\Delta} \mathbf{H}^{\mathbf{0}}$ & $\boldsymbol{\Delta S}^{\mathbf{0}}$ \\
\cline { 2 - 5 } & {$[\mathbf{K}]$} & {$[\mathbf{k J} / \mathbf{m o l}]$} & {$[\mathbf{k J} / \mathbf{m o l}]$} & \\
\hline \multirow{2}{*}{ CCP 20 } & 283 & -15.0 & -16.9 & -6.8 \\
& 295 & -15.0 & & \\
\hline \multirow{2}{*}{ Micro 200 } & 307 & -14.8 & -9.1 & \\
& 283 & -13.9 & & \\
\hline \multirow{2}{*}{ EcoZeo 20 } & 295 & -14.3 & & \\
& 307 & -14.2 & -4.7 & \\
& 283 & -13.7 & & \\
\hline
\end{tabular}

From the thermodynamic parameters determined, it can be concluded that due to the negative free reaction enthalpy $\Delta \mathrm{G}^{0}$ in the examined temperature range (283-307 K), the adsorption process of ammonium onto the investigated CLI was exergonic, i.e., a voluntary reaction. The free standard enthalpy $\Delta \mathrm{H}^{0}$ of all three sorbents was negative, indicating an exothermic reaction. The standard molar entropy $\Delta S^{0}$, which was positive for Micro 200 and EcoZeo 20, indicates that the ammonium adsorption is a directional process, decreasing slightly as the temperature increases. However, the negative molar standard entropy of CCP 20 indicates, that the sorption process was random.

An exergonic reaction was also observed by Alshameri et al. [14], Gunay [46], and Karadag et al. [19]. Their reported values of $\Delta \mathrm{G}^{0}$ ranged from -2.8662 to $0.224 \mathrm{~kJ} / \mathrm{mol}$ [14], -0.79 to $1.63 \mathrm{~kJ} / \mathrm{mol}$ [46], and -0.22 to $1.60 \mathrm{~kJ} / \mathrm{mol}[19]$, respectively. In this study, the values of $\Delta \mathrm{G}^{0}$ range from -15 to $-13.7 \mathrm{~kJ} / \mathrm{mol}$. The much lower values regarding $\Delta \mathrm{G}^{0}$ of this study can be attributed to the smaller particle size and therefore short diffusion pathways of cations into the CLI compared to the ones of Alshameri et al. [14], Gunay [46], and Karadag et al. [19], where zeolites with particle sizes of 0.063-0.074 mm, 0.3-0.6 mm, and 1.0-1.4 mm, respectively, were used. Furthermore, the values of $\Delta \mathrm{G}^{0}$ of the investigated CLIs decrease with increasing CEC, indicating that a high natural preload of the CLI with alkali and alkaline earth cations leads to a more exergonic adsorption. Similar to the results published by other researchers $\left(\Delta \mathrm{H}^{0}:-49.384,-22.34,-5.43\right.$, $-15.38 \mathrm{~kJ} / \mathrm{mol}[14,19,45,46])$, which indicate that adsorption of ammonium is exothermic, a slightly exothermic 
adsorption was found for the CLIs tested in this study $\left(\Delta \mathrm{H}^{0}\right.$ ranging from $4.7 \mathrm{~kJ} / \mathrm{mol}$ (EcoZeo 20) to 16.9 $\mathrm{kJ} / \mathrm{mol}(\mathrm{CCP} 20))$. Furthermore, results reported with negative values of $\Delta S^{0}(-156.1,-74.42,-43.03,-49.34$, $\mathrm{J} /(\mathrm{K} \mathrm{mol})[14,19,45,46])$ indicate decreasing ammonium uptake due to increasing randomness. In contrast to this, a strongly directed adsorption process, as indicated by positive $\Delta \mathrm{S}^{0}$ values ranging between $32.7 \mathrm{~J} /(\mathrm{K}$ $\mathrm{mol}$ ) (EcoZeo 20) and 17.6 J/(K mol) (Micro 200), was achieved with the investigated materials of this study.

The results of studies by other researchers show that at higher temperatures not every zeolite shows a good adsorption performance with regard to ammonium. This means that zeolites must be chosen well to suit each individual situation, e.g., for the treatment of wastewater in typical temperature ranges (e.g., 283-307 K). All the investigated materials of this study showed best adsorption properties at temperatures of $34^{\circ} \mathrm{C}$, so they are obviously well suited for the application of ammonium extraction from wastewater of this temperature level, e.g., sludge water from anaerobic mesophilic digesters.

\subsection{Kinetic Studies}

The results of the adsorption kinetics (loading $\mathrm{q}_{\mathrm{t}}$ as a function of the contact time) of the three sorbents in $\mathrm{NH}_{4} \mathrm{Cl}$ solution are depicted in Figure 4. Furthermore, the fit to the ID model, which achieved higher $\mathrm{r}^{2}$ values compared to the PSO model, is represented as lines.

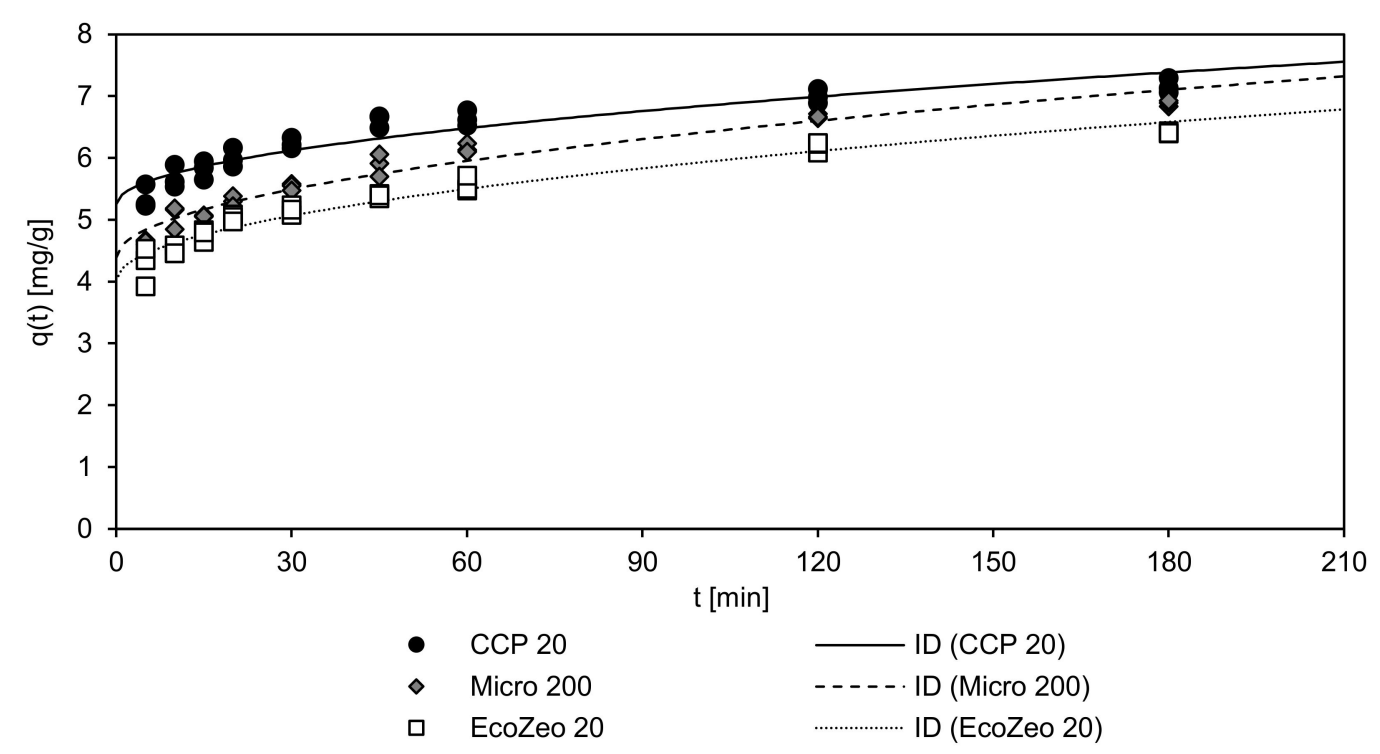

Figure 4. Loading of CCP 20, Micro 200, and EcoZeo 20 as a function of the contact time $\left(\mathrm{c}_{0}=1000 \mathrm{mg}\right.$ $\mathrm{NH}_{4}-\mathrm{N} / \mathrm{L}, \mathrm{pH}_{\text {Start }} 5.3, \mathrm{pH}_{\text {End }}$ 6.6-7.1, sorbent ratio $\left.0.1 \mathrm{~g}_{\mathrm{CLI}} / \mathrm{mg}_{\mathrm{NH} 4-\mathrm{N}}\right)$.

As shown in Figure 4, all CLIs are characterized by a rapid initial adsorption within the first minutes due to the thick boundary layer, which has a high capacity. Already after a contact time of $5 \mathrm{~min}$, a load of 4.0 to $5.5 \mathrm{mg} / \mathrm{g}$, which corresponds to $68 \%$ (100\% was achieved after $180 \mathrm{~min}$ contact time) in the case of Micro 200 and EcoZeo 20 and 76\% in the case of CCP 20, was achieved. After $60 \mathrm{~min}$, Micro 200 and EcoZeo 20 reached 84\% of their maximum load, while CCP 20 had already reached $88 \%$ at that time. As it was already shown in the isothermal studies (Chapter 3.3), CCP 20 achieved the highest loading in comparison to the other CLIs.

Table 8 summarizes the coefficients of the PSO model and ID model. The high coefficients of determination achieved by the ID model indicate that the adsorption speed is controlled by intraparticle diffusion. Fitting the obtained results to the PSO model reveals that CCP 20 achieved the highest adsorption rate $\left(\mathrm{k}_{2}=0.064 \mathrm{~g} /(\mathrm{mg} \mathrm{min})\right)$, followed by EcoZeo $20\left(\mathrm{k}_{2}=0.048 \mathrm{~g} /(\mathrm{mg} \mathrm{min})\right)$ and Micro $200\left(\mathrm{k}_{2}=0.046 \mathrm{~g} /(\mathrm{mg} \mathrm{min})\right)$. Equilibrium loading $\mathrm{q}_{\mathrm{e}}$ of CCP 20 was also highest $\left(\mathrm{q}_{\mathrm{e}}=6.99 \mathrm{mg} / \mathrm{g}\right)$, followed by Micro $200\left(\mathrm{q}_{\mathrm{e}}=6.62 \mathrm{mg} / \mathrm{g}\right)$ and EcoZeo $20\left(\mathrm{q}_{\mathrm{e}}=6.13 \mathrm{mg} / \mathrm{g}\right)$. According to the ID model, the intraparticle adsorption rate $\mathrm{k}_{\mathrm{ID}}$ of Micro 200 was highest $\left(0.203 \mathrm{mg} /\left(\mathrm{min}^{0.5} \mathrm{~g}\right)\right)$, followed by 
EcoZeo $20\left(0.191 \mathrm{mg} /\left(\min ^{0.5} \mathrm{~g}\right)\right)$ and CCP $20\left(0.159 \mathrm{mg} /\left(\mathrm{min}^{0.5} \mathrm{~g}\right)\right)$. Initial adsorption C, on the other hand, was the highest of CCP $20(5.25 \mathrm{mg} / \mathrm{g})$, followed by Micro $200(4.38 \mathrm{mg} / \mathrm{g})$ and EcoZeo 20 $(4.02 \mathrm{mg} / \mathrm{g})$. Thus, although the adsorption rates of Micro 200 and EcoZeo 20 were higher, neither CLIs reached the loading of CCP 20, which remained unattained due to the large initial adsorption by its thick boundary layer.

Table 8. Coefficients of adsorption kinetics according to the PSO and ID model of CCP 20, Micro 200, and EcoZeo 20 ( $\mathrm{c}_{0}=1000 \mathrm{mg} \mathrm{NH}-\mathrm{N} / \mathrm{L}, \mathrm{pH}_{\text {Start }} 5.3$, $\mathrm{pH}_{\text {End }} 6.6-7.1$, sorbent ratio $\left.0.1 \mathrm{~g}_{\mathrm{CLI}} / \mathrm{mg}_{\mathrm{NH} 4-\mathrm{N}}\right)$.

\begin{tabular}{ccccccc}
\hline \multirow{2}{*}{ CLI } & \multicolumn{2}{c}{ Pseudo-Second-Order Kinetic Model } & \multicolumn{3}{c}{ Intraparticle Diffusion Model } \\
\cline { 2 - 7 } & $\mathbf{k}_{\mathbf{2}}$ & $\mathbf{q}$ & $\mathbf{r}^{2}$ & $\mathbf{k}_{\mathbf{I D}}$ & $\mathbf{C}$ & $\mathbf{r}^{\mathbf{2}}$ \\
\cline { 2 - 7 } & {$[\mathbf{g} /(\mathbf{m g} \mathbf{m i n})]$} & {$[\mathbf{m g} / \mathbf{g}]$} & {$[-]$} & {$\left[\mathbf{m g} /\left(\mathbf{m i n}^{\mathbf{0 . 5}} \mathbf{g}\right)\right]$} & {$[\mathbf{m g} / \mathbf{g}]$} & {$[-]$} \\
\hline CCP 20 & 0.064 & 6.99 & 0.8319 & 0.159 & 5.25 & 0.8852 \\
Micro 200 & 0.046 & 6.62 & 0.8101 & 0.203 & 4.38 & 0.9520 \\
EcoZeo 20 & 0.048 & 6.13 & 0.8158 & 0.191 & 4.02 & 0.9473 \\
\hline
\end{tabular}

The results of the PSO model confirm already published conclusions according to which a high initial ammonium concentration leads to a high equilibrium load $\mathrm{q}_{\mathrm{e}}$ but a slow adsorption rate $\mathrm{k}_{2}$ [22,47,48]. Thus, the adsorption velocities found in this study were slower than those reported by Karadag et al. [47] $\left(\mathrm{k}_{2}=0.526 \mathrm{~g} /(\mathrm{mg} \mathrm{min}), \mathrm{c}_{0}=100 \mathrm{mg} / \mathrm{L}\right)$ and Moussavi et al. [48] $\left(\mathrm{k}_{2}=0.096 \mathrm{~g} /(\mathrm{mg} \mathrm{min}), \mathrm{c}_{0}=100 \mathrm{mg} / \mathrm{L}\right)$, but exceeded those of Erdogan and Ülkü [22] $\left(\mathrm{k}_{2}=0.6 \times 10^{-3} \mathrm{~g} /(\mathrm{mg} \mathrm{min}), \mathrm{c}_{0}=300 \mathrm{mg} / \mathrm{L}\right)$ significantly.

Micro 200, the particle size distribution of which extends over a wider range, adsorbed ammonium more slowly than the other two CLIs. This confirms the results of Erdogan and Ülkü [22] and Huang et al. [49], who achieved the fastest adsorption velocity $\mathrm{k}_{2}$ with the smallest particles. Therefore, sorbent particles should always be as small as practicable in order to achieve a high adsorption rate.

\section{Conclusions}

Within the scope of the investigations, the adsorption of ammonium by three different CLIs (CCP 20, Micro 200, and EcoZeo 20) at different $\mathrm{pH}$ values, different amounts of sorbent mass, different temperatures, and different contact times were systematically investigated. All three CLIs tested were very effective at adsorbing ammonium. In a $\mathrm{pH}$ range from 2 to 8 , the CLIs were able to eliminate ammonium equally well, whereas higher $\mathrm{pH}$ values led to a significant drop in elimination. The CLI CCP 20 achieved the highest loading compared to Micro 200 and EcoZeo 20. This can be attributed to its small particle size, the highest CEC, and the highest natural preloading of the sorbent with $\mathrm{K}^{+}$ and $\mathrm{Na}^{+}$cations of all CLIs tested. The isoelectric state of the CLIs was in the alkaline range, resulting from a large negative charge attracting cations as well as leaching of alkali and earth alkali cations influencing the $\mathrm{pH}$. Furthermore, a contact time of 60 minutes was sufficient to achieve $84-88 \%$ of the maximum load. At a temperature of $34^{\circ} \mathrm{C}$, the highest loading was achieved (investigated range: $10-34{ }^{\circ} \mathrm{C}$ ). The adsorption process of all CLIs was of exergonic and exothermic nature. Especially for those types of wastewater streams with high ammonium concentrations such as sludge water from anaerobic sludge digesters operated at mesophilic temperatures, CLI proved to be a suitable sorbent for the elimination of ammonium. Both the CEC determination and the determination of the isoelectric state are simple and fast methods to assess qualitatively the adsorption capacity of a CLI. In this study, CCP 20, which has the largest CEC and lowest isoelectric state, achieved the highest adsorption capacity. Depending on the research objective, the investigation of the CEC and the isoelectric point can provide sufficient information about the adsorption behavior of CLI.

Further investigations with real wastewater should be carried out. 
Author Contributions: S.W. conceived, designed, performed the experiments and analyzed the data; S.W., E.R., R.M. and H.S. discussed the results and wrote the paper.

Acknowledgments: This work was sponsored by the Federal Ministry of Economic Affairs and Energy following a resolution of the German Parliament. The CLIs were provided by Fluidtec, Kempenich, Germany.

Conflicts of Interest: The authors declare no conflict of interest. The founding sponsors had no role in the design of the study; in the collection, analyses, or interpretation of data; in the writing of the manuscript, and in the decision to publish the results.

\section{References}

1. United Nations. World Population Prospects: The 2017 Revision, Key Findings and Advance Tables; Working Paper No. ESA/P/WP/248; United Nations: New York, NY, USA, 2017.

2. Food and Agriculture Organization (FAO). The Future of Food and Agriculture-Trends and Challenges; FAO: Rome, Italy, 2017.

3. Erisman, J.W.; Sutton, M.A.; Galloway, J.; Klimont, Z.; Winiwarter, W. How a century of ammonia synthesis changed the world. Nat. Geosci. 2008, 1, 636-639. [CrossRef]

4. Appl, M. Ammonia. In Ulmann's Encyclopedia of Industrial Chemistry: Ammonia; Wiley-VCH Verlag GmbH \& Co. KGaA: Weinheim, Germany, 2000.

5. Dawson, C.J.; Hilton, J. Fertiliser availability in a resource-limited world: Production and recycling of nitrogen and phosphorus. Food Policy 2011, 36, S14-S22. [CrossRef]

6. Sengupta, S.; Nawaz, T.; Beaudry, J. Nitrogen and Phosphorus Recovery from Wastewater. Curr. Pollut. Rep. 2015, 1, 155-166. [CrossRef]

7. Englert, A.H.; Rubio, J. Characterization and environmental application of a Chilean natural zeolite. Int. J. Miner. Process. 2005, 75, 21-29. [CrossRef]

8. Weatherley, L.R.; Miladinovic, N.D. Comparison of the ion exchange uptake of ammonium ion onto New Zealand clinoptilolite and mordenite. Water Res. 2004, 38, 4305-4312. [CrossRef] [PubMed]

9. Cyrus, J.S.; Reddy, G.B. Sorption and desorption of ammonium by zeolite: Batch and column studies. J. Environ. Sci. Health Part A Tox./Hazard. Subst. Environ. Eng. 2011, 46, 408-414. [CrossRef] [PubMed]

10. Guaya, D.; Valderrama, C.; Farran, A.; Armijos, C.; Cortina, J.L. Simultaneous phosphate and ammonium removal from aqueous solution by a hydrated aluminum oxide modified natural zeolite. Chem. Eng. J. 2015, 271, 204-213. [CrossRef]

11. Karadag, D.; Tok, S.; Akgul, E.; Turan, M.; Ozturk, M.; Demir, A. Ammonium removal from sanitary landfill leachate using natural Gördes clinoptilolite. J. Hazard. Mater. 2008, 153, 60-66. [CrossRef] [PubMed]

12. Zhang, H.; Li, A.; Zhang, W.; Shuang, C. Combination of Na-modified zeolite and anion exchange resin for advanced treatment of a high ammonia-nitrogen content municipal effluent. J. Colloid Interface Sci. 2016, 468, 128-135. [CrossRef] [PubMed]

13. Du, Q.; Liu, S.; Cao, Z.; Wang, Y. Ammonia removal from aqueous solution using natural Chinese clinoptilolite. Sep. Purif. Technol. 2005, 44, 229-234. [CrossRef]

14. Alshameri, A.; Yan, C.; Al-Ani, Y.; Dawood, A.S.; Ibrahim, A.; Zhou, C.; Wang, H. An investigation into the adsorption removal of ammonium by salt activated Chinese (Hulaodu) natural zeolite: Kinetics, isotherms, and thermodynamics. J. Taiwan Inst. Chem. Eng. 2014, 45, 554-564. [CrossRef]

15. Lin, L.; Lei, Z.; Wang, L.; Liu, X.; Zhang, Y.; Wan, C.; Lee, D.; Tay, J.H. Adsorption mechanisms of high-levels of ammonium onto natural and NaCl-modified zeolites. Sep. Purif. Technol. 2013, 103, 15-20. [CrossRef]

16. Vassileva, P.; Voikova, D. Investigation on natural and pretreated Bulgarian clinoptilolite for ammonium ions removal from aqueous solutions. J. Hazard. Mater. 2009, 170, 948-953. [CrossRef] [PubMed]

17. Wang, Y.-F.; Lin, F.; Pang, W.Q. Ammonium exchange in aqueous solution using Chinese natural clinoptilolite and modified zeolite. J. Hazard. Mater. 2007, 142, 160-164. [CrossRef] [PubMed]

18. Saltali, K.; Sari, A.; Aydin, M. Removal of ammonium ion from aqueous solution by natural Turkish (Yildizeli) zeolite for environmental quality. J. Hazard. Mater. 2007, 141, 258-263. [CrossRef] [PubMed]

19. Karadag, D.; Koc, Y.; Turan, M.; Armagan, B. Removal of ammonium ion from aqueous solution using natural Turkish clinoptilolite. J. Hazard. Mater. 2006, 136, 604-609. [CrossRef] [PubMed]

20. Sarioglu, M. Removal of ammonium from municipal wastewater using natural Turkish (Dogantepe) zeolite. Sep. Purif. Technol. 2005, 41,1-11. [CrossRef] 
21. Temel, F.A.; Kuleyin, A. Ammonium removal from landfill leachate using natural zeolite: Kinetic, equilibrium, and thermodynamic studies. Desalination Water Treat. 2016, 57, 23873-23892. [CrossRef]

22. Erdoğan, B.C.; Ülkü, S. Ammonium sorption by Gördes clinoptilolite rich mineral specimen. Appl. Clay Sci. 2011, 54, 217-225. [CrossRef]

23. Freundlich, H. Über die Adsorption in Lösungen. Z. Phys. Chem. 1907, 57, 385-470. [CrossRef]

24. Ho, Y.-S.; Porter, J.F.; McKay, G. Equilibrium isotherm studies for the sorption of divalent metal ions onto peat: copper, nickel an dlead single component systems. Water Air Soil Pollut. 2002, 141, 1-33. [CrossRef]

25. Langmuir, I. The Adsorption of Gases on Plane Surfaces of Glass, Mica and Platinum. J. Am. Chem. Soc. 1918, 40,1361-1403. [CrossRef]

26. Kinniburgh, D.G. General purpose adsorption isotherms. Environ. Sci. Technol. 1986, 20, 895-904. [CrossRef] [PubMed]

27. Chen, X. Modeling of Experimental Adsorption Isotherm Data. Information 2015, 6, 14-22. [CrossRef]

28. Tempkin, M.I.; Pyzhev, V. Kinetics of ammonia synthesis on promoted iron catalyst. Acta Physicochim. USSR 1940, 12, 217-222.

29. Dada, A.O.; Olalekan, A.P.; Olatunya, A.M.; Dada, O. Langmuir, Freundlich, Temkin and Dubinin-Radushkevich Isotherms Studies of Equilibrium Sorption of $\mathrm{Zn}^{2+}$ Unto Phosphoric Acid Modified Rice Husk. IOSR J. Appl. Chem. 2012, 3, 38-45.

30. Aharoni, C.; Ungarish, M. Kinetics of activated chemisorption. Part 2.-Theoretical models. J. Chem. Soc. Faraday Trans. 1 1977, 73, 456-464. [CrossRef]

31. Milonjic, S. A consideration of the correct calculation of thermodynamic parameters of adsorption. J. Serb. Chem. Soc. 2007, 72, 1363-1367. [CrossRef]

32. Weber, W.J.; Morris, J.C. Kinetics of Adsorption on Carbon from Solution. J. Sanit. Eng. Div. 1963, 89, 31-60.

33. Qiu, H.; Lv, L.; Pan, B.; Zhang, Q.; Zhang, W. Critical review in adsorption kinetic models. J. Zhejiang Univ. Sci. A 2009, 10, 716-724. [CrossRef]

34. McKay, G.; Otterburn, M.S.; Sweeney, A.G. The removal of colour from effluent using various adsorbents, III. Silica: Rate Processes. Water Res. 1980, 14, 15-20. [CrossRef]

35. Ho, Y.-S.; McKay, G. A Comparison of Chemisorption Kinetic Models Applied to Pollutant Removal on Various Sorbents. Process Saf. Environ. Prot. 1998, 76, 332-340. [CrossRef]

36. Ho, Y.-S. Second-order kinetic model for the sorption of cadmium onto tree fern: A comparison of linear and non-linear methods. Water Res. 2006, 40, 119-125. [CrossRef] [PubMed]

37. DIN Deutsches Institut für Normung E.V. DIN 38406-5. German Standard Methods for the Examination of Water, Waste Water and Sludge; Cations (Group E); Determination of Ammonia-Nitrogen (E 5); German Institute for Standardization: Berlin, Germany, 1983.

38. Malekian, R.; Abedi-Koupai, J.; Eslamian, S.S.; Mousavi, S.F.; Abbaspour, K.C.; Afyuni, M. Ion-exchange process for ammonium removal and release using natural Iranian zeolite. Appl. Clay Sci. 2011, 51, 323-329. [CrossRef]

39. Zhang, Y.; Bi, E. Effect of dissolved organic matter on ammonium sorption kinetics and equilibrium to Chinese clinoptilolite. Environ. Technol. 2012, 33, 2395-2403. [CrossRef] [PubMed]

40. Li, M.; Zhu, X.; Zhu, F.; Ren, G.; Cao, G.; Song, L. Application of modified zeolite for ammonium removal from drinking water. Desalination 2011, 271, 295-300. [CrossRef]

41. Guo, X.; Zeng, L.L.; Li, X.; Park, H.-S. Ammonium and potassium removal for anaerobically digested wastewater using natural clinoptilolite followed by membrane pretreatment. J. Hazard. Mater. 2008, 151, 125-133. [CrossRef] [PubMed]

42. Alshameri, A.; Ibrahim, A.; Assabri, A.M.; Lei, X.; Wang, H.; Yan, C. The investigation into the ammonium removal performance of Yemeni natural zeolite: Modification, ion exchange mechanism, and thermodynamics. Powder Technol. 2014, 258, 20-31. [CrossRef]

43. Mazloomi, F.; Jalali, M. Ammonium removal from aqueous solutions by natural Iranian zeolite in the presence of organic acids, cations and anions. J. Environ. Chem. Eng. 2016, 4, 240-249. [CrossRef]

44. Ji, Z.Y.; Yuan, J.S.; Li, X.G. Removal of ammonium from wastewater using calcium form clinoptilolite. J. Hazard. Mater. 2007, 141, 483-488. [CrossRef] [PubMed]

45. Tosun, I. Ammonium removal from aqueous solutions by clinoptilolite: Determination of isotherm and thermodynamic parameters and comparison of kinetics by the double exponential model and conventional kinetic models. Int. J. Environ. Res. Public Health 2012, 9, 970-984. [CrossRef] [PubMed] 
46. Gunay, A. Application of nonlinear regression analysis for ammonium exchange by natural (Bigadic) clinoptilolite. J. Hazard. Mater. 2007, 148, 708-713. [CrossRef] [PubMed]

47. Karadag, D.; Koc, Y.; Turan, M.; Ozturk, M. A comparative study of linear and non-linear regression analysis for ammonium exchange by clinoptilolite zeolite. J. Hazard. Mater. 2007, 144, 432-437. [CrossRef] [PubMed]

48. Moussavi, G.; Talebi, S.; Farrokhi, M.; Sabouti, R.M. The investigation of mechanism, kinetic and isotherm of ammonia and humic acid co-adsorption onto natural zeolite. Chem. Eng. J. 2011, 171, 1159-1169. [CrossRef]

49. Huang, H.; Xiao, X.; Yan, B.; Yang, L. Ammonium removal from aqueous solutions by using natural Chinese (Chende) zeolite as adsorbent. J. Hazard. Mater. 2010, 175, 247-252. [CrossRef] [PubMed]

2018 by the authors. Licensee MDPI, Basel, Switzerland. This article is an open access article distributed under the terms and conditions of the Creative Commons Attribution (CC BY) license (http://creativecommons.org/licenses/by/4.0/). 